\title{
CARDIAC FAILURE DUE TO PRIMARY AMYLOIDOSIS
}

BY

\author{
HEATHER ASHTON
}

From the Department of Cardiology, the Middlesex Hospital

Primary amyloidosis is considered to be a rare disease. In 1939 Lindsay and Knorp reviewed 49 cases, and since then approximately 30 more have been recorded. The condition is important in the differential diagnosis of congestive cardiac failure of obscure origin. It may present a difficult clinical problem, as in the case reported here.

\section{Case Report}

In September, 1953, a woman of 46 years, who had previously been well, developed swelling of the ankles. This gradually increased until in February, 1954, she was admitted to hospital. She was treated in bed with a low sodium diet and mersalyl, and in March she was discharged home, free from oedema. Two months later the symptoms returned and she was readmitted. The congestive failure again responded to rest and mersalyl. She was transferred to the Middlesex Hospital in August with a diagnosis of either constrictive pericarditis or myocarditis with failure.

She was a pale, well-covered woman with a slightly hoarse voice. Pulse regular, 96 a minute. Blood pressure, $110 / 80$. Venous pulsation was visible one inch above the sternal angle at $45^{\circ}$, and the liver was enlarged three finger breadths below the costal margin. There was ascites and gross odema of sacrum and legs. There were no palpable cardiac pulsations. The heart sounds were faint. There was an apical presystolic gallop but no murmurs were heard. The lungs were dry and the spleen was impalpable.

Urine: heavy albuminuria; total urinary protein $10.9 \mathrm{~g}$. in $24 \mathrm{hr}$.; deposit: some leucocytes, epithelial cells, and hyaline casts in some specimens. Electrocardiogram showed sinus rhythm and low voltage QRS complexes with flat $T$ waves. Chest $X$-ray: increased transverse diameter of heart; lung fields clear; no pericardial calcification. Radioscopy: diminished cardiac pulsation. Blood count and hæmoglobin normal. E.S.R., $39 \mathrm{~mm}$. in one hour. W.R. negative.

Blood urea normal. Urea clearance, renal function 49 per cent. Serum cholesterol, $560 \mathrm{mg}$. per $100 \mathrm{ml}$. Serum proteins, total, $4 \cdot 7 \mathrm{~g}$. per $100 \mathrm{ml}$. (albumin $2 \cdot 1$; globulin $2 \cdot 6$ ). Electrophoretic pattern of serum proteins showed grossly increased alpha 2 band. No amyloid seen in gum biopsy, and no "L.E." cells in blood smear. B.M.R., plus 1 per cent.

Cardiac catheterization and angiocardiography were unsuccessful because of a venous anomaly which prevented the catheter from being passed beyond the neck.

In spite of treatment in bed with a low sodium high protein diet, mercurial diuretics, and katonium, the œdema increased rapidly and heavy albuminuria continued. Acupuncture was performed and 17 pints of œdema fluid were drained from the legs in 24 hours. Drainage was then discontinued as the patient became drowsy and complained of nausea. The serum electrolytes at that time were within normal limits. The venous pressure remained raised and she continued to retain fluid. The blood urea rose from normal to $79 \mathrm{mg}$. per $100 \mathrm{ml}$. On November 16, auricular fibrillation commenced and the blood pressure dropped to $90 / 60 \mathrm{~mm}$. Hg. Suddenly death took place on November 26 .

Necropsy. There was congestive cardiac failure with 5 pints of ascitic fluid, systemic œdema, and a nutmeg liver. No evidence of pericardial fibrosis was found, but there was generalized hypertrophy of the myocardium which contained a number of greyish waxy plaques. The lungs, kidneys, and spleen appeared normal. There was no evidence of chronic suppuration or tuberculosis.

Histology. The myocardium was infiltrated by an amyloid-like substance, deposited in the walls of capillaries and arterioles and around the myocardial fibres. Deposits of a similar material were present in the walls of capillaries, arterioles, and small arteries throughout the body, particularly those of the liver, spleen, suprarenals, and tongue. There was heavy infiltration of the basement membrane of sweat glands 
and some of the thyroid acini. The same substance was present in the basement membrane of the renal glomerular tufts and in the walls of the afferent arterioles. Some renal tubules showed hyaline degenerative changes.

The infiltrating material had the morphological appearance of amyloid, but failed to take up the usual dyes. It stained normally with hæmotoxylin and eosin but did not stain metachromatically with methyl violet. There was no affinity for iodine and only a slight affinity for Congo red. No reaction was seen with the per-iodic acid Schiff technique, as would have been expected in a collagen disease. In view of its typical appearance with hæmotoxylin and eosin and its distribution, there was little doubt that this was either amyloid or a very closely related substance.

\section{Discussion}

Primary systemic amyloidosis was first described by Lubarsch (1929), who formulated the following criteria for the condition: (1) the absence of a predisposing factor such as chronic suppuration, (2) the failure of the amyloid deposit to show the usual staining reactions, (3) the absence of involvement of organs commonly affected by secondary amyloid, and (4) extensive deposits in the heart, blood vessels, skin, and skeletal muscle.

The present case fulfils the first and second criteria. Concerning the third and fourth criteria, the common sites of secondary amyloidosis include the parenchymatous organs such as the spleen, kidney, liver, and adrenals. In primary amyloidosis, however, these organs tend to be spared, while the cardiovascular system, muscle, skin, lungs, and gastrointestinal tract are extensively involved. In the present case, the parenchymatous organs as well as the cardiovascular system and skin were involved, thus combining some of the features of both primary and secondary amyloidosis. A similar case was recorded by Hartney et al. (1949).

The electrophoretic pattern of the serum proteins was of particular interest, as it showed a greatly increased alpha 2 band, a pattern typical of the nephrotic syndrome. This abnormality, combined with the heavy proteinuria and the high serum cholesterol $(560 \mathrm{mg}$. per $100 \mathrm{ml}$.$) , suggested$ that considerable amyloid deposits would be found in the kidneys. Microscopy confirmed generalized renal infiltration of moderate degree. An increase in the alpha 2 fraction may also occur in congestive cardiac failure and in constrictive pericarditis (Hardwicke, 1954), and the cardiac failure may have contributed to the electrophoretic pattern in the present case. In regard to the raised serum cholesterol, it may be significant that the thyroid gland was also involved. Again, the heavy amyloidosis of the liver may have been a factor in the serum cholesterol level, and could account for the altered albumin: globulin ratio $(2 \cdot 1: 2 \cdot 6)$.

In primary amyloidosis a presenting picture of congestive cardiac failure due to myocardial involvement is not uncommon. Dahlin (1949) states that death from cardiac causes occurs in over half these cases. This condition should therefore be considered in cases of congestive failure which prove refractory to the standard treatment or in which the underlying ætiology is obscure. Constrictive pericarditis or pericardial effusion may enter into the differential diagnosis, as in the present case, in which a raised venous pressure and generalized œedema were combined with a quiet impalpable heart. The question of operative treatment then arises. The presence of pericardial calcification on radioscopy will confirm the diagnosis of constrictive pericarditis. In equivocal cases, cardiac catheterization or angiocardiography may be necessary. A characteristic pulse form in the right ventricle and right atrium is obtained in constrictive pericarditis (McKusick, 1952). Injection of contrast medium through the catheter in the right atrium will demonstrate a thickened pericardium or a pericardial effusion (Wood, 1951). In the present case, neither of these tests could be performed, and the diagnosis was in doubt until necropsy.

A positive diagnosis of primary amyloidosis may sometimes be made by means of the Congo red test (Bennhold, 1923; Wade, 1954) or by the recovery of amyloid tissue from gum, skin, or muscle biopsy. Negative results, however, do not exclude the diagnosis, as shown by the gum biopsy in the present case. 


\section{Summary}

A fatal case of primary systemic amyloidosis is recorded, in which myocardial involvement caused congestive cardiac failure.

I wish to thank Dr. R. Howard who referred the case to hospital, Dr. W. Somerville under whose care the patient was admitted to the Middlesex Hospital, and Dr. P. Andrews for the post-mortem examination.

\section{References}

Bennhold, H. (1923). Dtsch. Arch. klin. Med., 142, 32.

Dahlin, D. C. (1949). Amer. J. Path., 25, 105.

Hardwicke, J. (1954). Proc. roy. Soc. Med., 47, 832.

Hartney, J. B., Biederman, A. A., Blumberg, J. M., and Leedham, C. L. (1949). Arch. Path., 47, 598.

Lubarsch, O. (1929). Virchow's Arch. path. Anat., 271, 867.

McKusick, V. A. (1952). Bull. Johns Hopkins Hosp., 90, 27.

Wade, G. (1954). Medicine Illustrated, 8, 592.

Wood, P. (1951). Brit. Heart J., 13, 574. 